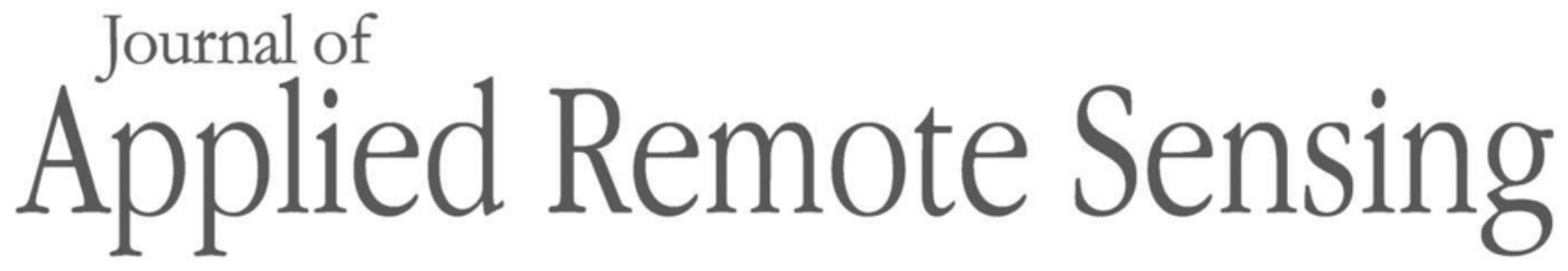

\title{
Assessment of quasi-analytical algorithm for estimating the inherent optical properties in a complex cascade system
}

Caroline Andrade

Nariane Bernardo

Alisson Carmo

Enner Alcântara

Milton Kampel 


\title{
Assessment of quasi-analytical algorithm for estimating the inherent optical properties in a complex cascade system
}

\author{
Caroline Andrade, ${ }^{\mathrm{a}}$ Nariane Bernardo, ${ }^{\mathrm{a}}$ Alisson Carmo, ${ }^{\mathrm{a}}$ \\ Enner Alcântara, ${ }^{\text {b }}$ 网 and Milton Kampel ${ }^{\mathrm{c}}$ \\ ${ }^{a}$ São Paulo State University, Department of Cartography, Presidente Prudente, Brazil \\ 'São Paulo State University, Department of Environmental Engineering, \\ São José dos Campos, Brazil \\ ${ }^{\mathrm{c}}$ National Institute for Space Research, Remote Sensing Division, São José dos Campos, Brazil
}

\begin{abstract}
Several quasi-analytical algorithm (QAA) versions were developed to make it suitable for different inland water systems. $\mathrm{QAA}_{\mathrm{BBHR}}$ and $\mathrm{QAA}_{\mathrm{OMW}}$ were reparameterized based on two reservoirs from the Tietê River cascading system (São Paulo State, Brazil), which present widely differing compositions. Considering the purpose of monitoring the entire cascade through a unique QAA version, we aimed to assess the suitability of these two QAA versions and, in addition, another two QAA native forms (versions 5 and 6), for retrieving inherent optical properties (IOPs) in Ibitinga hydroelectric reservoir (IHR), situated in the same cascading system. In addition to that, we addressed bio-optical characterization of IHR, using spectral and water quality data collected in a field campaign conducted in July 2016. Wide spatial variability of optically significant constituent (OSC) in IHR and colored dissolved organic matter predominance in its absorption budget was observed. None of the tested QAA versions were completely suitable in retrieving absorption coefficients for IHR in all wavelengths. However, results for wavelengths commonly used as proxy for OSC concentration retrieval were satisfactory in some of the models. Therefore, the results obtained in this study shows that QAAs versions can be used for specific purposes (e.g., chlorophyll- $a$ mapping), by employing the best model for IOPs retrieval at a specific wavelength. This highlights the challenge of copying with high optical variability in cascading systems. In this sense, further research is necessary, for either achieving a QAA reparameterized version appropriate for aquatic systems with widely differing optical properties or another analytical scheme. (C) 2018 Society of Photo-Optical Instrumentation Engineers (SPIE) [DOI: 10.1117/1].JRS.124036014]
\end{abstract}

Keywords: bio-optical models; water quality; water resources monitoring; remotely sensed data.

Paper 180369L received May 3, 2018; accepted for publication Aug. 17, 2018; published online Sep. 4, 2018.

\section{Introduction}

Remotely sensed data have been used to retrieve the optically significant compounds (OSC) concentrations in inland waters, using bio-optical models. These models are often empirical or semianalytical models. Empirical models directly relate remotely sensed measurements to the OSC of interest, usually through statistical regression, whereas semianalytical is based on radiative transfer inverse modeling. Empirical models can be time and site limited with no physical meaning.

Semianalytical and quasianalytical algorithms (QAA) ${ }^{\square}$ are based on radiative transfer theory and often include empirical steps. A semianalytical model estimates the total absorption coefficient $a_{t}(\lambda)$ by sum of phytoplankton absorption coefficient, $a_{\varphi}(\lambda)$, colored dissolved organic matter (CDOM) absorption coefficient, $a_{\mathrm{CDOM}}(\lambda)$, and nonalgal particle absorption coefficient, $a_{\mathrm{NAP}}(\lambda)^{\mathrm{Q}} \mathrm{B}$ while QAA estimates $a_{t}(\lambda)$ using exclusively remote sensing reflectance $\left(R_{r s}\right)$.

*Address all correspondence to: Enner Alcântara, E-mail: enner[alcantara@unesplbr 
The backscattering coefficient, $b_{b}(\lambda)$, is also estimated via semianalytical models by summing $b_{b}$ of each in-water constituent, except CDOM, whereas QAA also retrieves backscattering coefficient of suspended particles $b_{b p}(\lambda)$ using $R_{r s}$, though analytical and empirical steps.

QAA is a special case because it includes empirical and analytical steps for retrieving inherent optical properties (IOPs) and was developed to retrieve IOPs in the open ocean and coastal waters, and later for turbid waters. There are mainly three limitations of QAA applicability in inland waters: (1) the model used to estimate the $a_{t}(\lambda)$ is empirically derived from synthetic data, (2) the model used to estimate $\eta$-spectral power for $b_{b p}(\lambda)$ derivation, and (3) the equations used to estimate the phytoplankton absorption coefficient.

The applicability of QAA in optically complex inland waters is certainly more challenging than when working on case 1 waters. . To make QAA suitable for more complex waters, calibration and reparameterization of the original versions are required as demonstrated by several authors. $\mathrm{F}$ Considering that at shorter wavelengths, $a_{t}$ is highly influenced by $a_{\varphi}$ and CDOM plus detritus absorption coefficient, $a_{\mathrm{CDM}}$, in inland waters, reparameterization includes reference wavelength $\left(\lambda_{0}\right)$ shifting to red-edge and near-infrared regions. 6 四 In addition to that, other usual enhancements in inland water QAA versions are a calibration of intermediary empirical and semianalytical steps, such as $a_{t}\left(\lambda_{0}\right)$ and $b_{b p}(\lambda)$ estimation, and reparameterization of equations or coefficients for $a_{\varphi}$ and $a_{\mathrm{CDM}}$ estimation, according to the IOPs presented in the specific inland water body.

When it comes to cascading reservoirs systems, variability trends are also influenced by cascading effects, $\square$ as well as by the different contributions arriving from the drainage basin, tributary rivers, and floodgates mechanisms ${ }^{12}$ In such aquatic systems, there are widely differing optical properties and the efficiency of parameterized versions is uncertain.

Tietê River cascading system is located in São Paulo state, a densely populated region of Brazil where water quality is an urgent matter. Recently, two QAA versions were parameterized

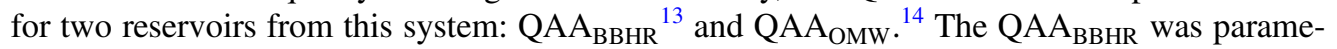
terized for the eutrophic Barra Bonita hydroelectric reservoir (BBHR) $\$$ which is the first reservoir of the cascading system, receiving large amounts of pollutants from the metropolis of São Paulo and also from agriculture and cattle raising $\square$ Suspended particulate matter (SPM) in this reservoir is dominated by the organic fraction. ${ }^{2}$ The $\mathrm{QAA}_{\mathrm{OMw}}$ version was parameterized for the oligo-to-mesotrophic Nova Avanhandava reservoir (NHR), located further downstream, presenting relatively low chlorophyll- $a(\mathrm{Chl}-a)$ and SPM concentrations, and inorganic predominance in its SPM.

Ibitinga hydroelectric reservoir (IHR) is also situated in the Tietê River, downstream from BBHR and upstream from NHR. Chl- $a$ and SPM concentration values in IHR are typically between the ranges found in BBHR and NHR. ${ }^{-1}$ However, due to some particularities, as organic matter predominance and slightly higher Chl- $a$ concentrations, IHR is possibly more similar to BBHR bio-optical characteristics. Considering that IHR bio-optical status is comparable with BBHR ones, the hypothesis here tested is that $\mathrm{QAA}_{\mathrm{BBHR}}$ could be able to consistently retrieve $a_{\varphi}$ in IHR but may be not capable of accurately retrieve $a_{\mathrm{CDM}}$, as $\mathrm{QAA} \mathrm{BBHR}_{\mathrm{B}}$ was parameterized considering phytoplankton features of the BBHR reservoir. ${ }^{3}$

To test the aforementioned hypothesis, we aim to assess the performance of $\mathrm{QAA}_{\mathrm{BBHR}}$ and

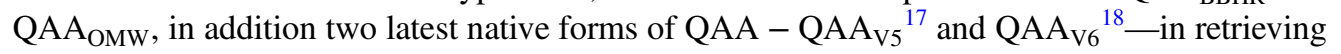
$a_{\varphi}$ and $a_{\mathrm{CDM}}$ for IHR; we also will retrieve $a_{t}$ for each QAA version. We decided to also test the $\mathrm{QAA}_{\mathrm{V} 5}$ and $\mathrm{QAA}_{\mathrm{V} 6}$ to compare the results from the original and reparameterized versions. This investigation relates to the purpose of monitoring all the cascading system in an integrated manner, through a unique QAA version properly adjusted for capturing the bio-optical variability occurring along the system. We also addressed water quality and bio-optical characterization of IHR, intending to associate it with algorithms efficiency, as this was not previously reported in the literature.

\section{Materials and Methods}

\subsection{Study Area}

IHR is located in the middle course of Tietê River, central area of São Paulo State, Brazil (21 $45^{\prime}$ $\mathrm{S}$ and $48^{\circ} 59^{\prime} \mathrm{W}$ ). It is the third of six cascading reservoirs [Fig. 1(a)]. Its flooded area is around 


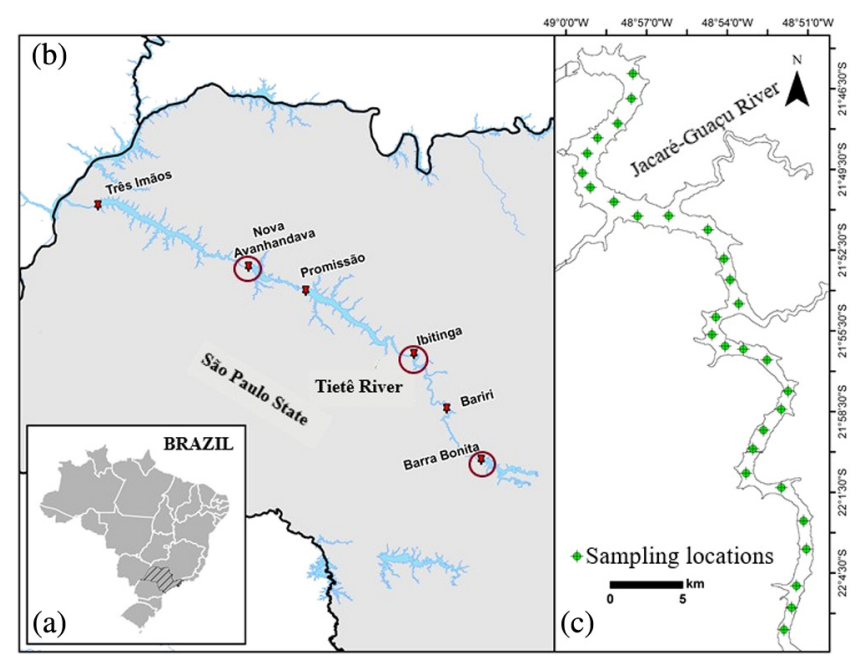

Fig. 1 (a) São Paulo State location in Brazil, (b) cascading reservoirs in Tietê River. Please note the IHR upstream from NHR and downstream from Barra Bonita reservoir (see text for more details), and (c) distribution of 29 sampling stations in IHR.

$114 \mathrm{~km}^{2}$, with $\sim 9 \mathrm{~m}$ of average depth and an average flow of $525 \mathrm{~m}^{3} \mathrm{~s}^{-1}$. IHR is situated in a temperate humid climate, characterized by well-defined dry and wet seasons. The surrounding area presents grazing land, sugarcane crops, and minor reforestation areas. 19 The river receives wastewater discharges from domestic and industrial sources along its course, besides diffuse sources of pollution arising from agriculture and cattle breeding activities. The trophic state of the reservoir is highly spatially and temporally variable, and some areas are classified as eutrophic, whereas other ones are considered mesotrophic. 100 A field campaign was conducted during austral winter, from July 19 to 23, 2016, in which water quality and spectral data were obtained in 29 sampling stations [Fig. [1(c)], as well as water samples collected just below air-water interface.

\subsection{Water Quality Data}

Secchi disk depth (m), turbidity (NTU), and electric conductivity $(\mu \mathrm{s} / \mathrm{cm})$ data were obtained in all 29 sampling stations [Fig. [1(c)]. Water samples were collected to estimate Chl- $a$ concentration, through acetone extraction method. 미르 The SPM concentrations, as well as organic (OSM) and inorganic suspended matter (ISM) fractions were estimated according to the American Public Health Association protocol. ${ }^{23}$

\subsection{Radiometric Data}

Total upwelling radiance $\left[L_{t}(\lambda) ; \mathrm{W} \mathrm{m}^{-2} \mathrm{sr}^{-1} \mathrm{~nm}^{-1}\right]$ and atmospheric diffuse radiance $\left[L_{s}(\lambda)\right.$; $\mathrm{W} \mathrm{m}{ }^{-2} \mathrm{sr}^{-1} \mathrm{~nm}^{-1}$ ] were measured using two RAMSES-ARC hyperspectral radiometers. Downwelling irradiance $\left[E_{d}(\lambda) ; \mathrm{W} \mathrm{m}^{-2} \mathrm{~nm}^{-1}\right]$ was measured using a RAMSES-ACC sensor (TriOS, Oldenburg, Germany). All radiometric sensors used were operated in the spectral range between 350 and $900 \mathrm{~nm}$, with a spectral resolution of $3.3 \mathrm{~nm}$. The acquisition geometry followed Ref. 24, with $L_{t}(\lambda)$ measured at a zenith angle $(\theta)$ of $140 \mathrm{deg}, L_{s}(\lambda)$ at $\theta=40 \mathrm{deg}$, and $E_{d}(\lambda)$ measured with the sensor aligned to the zenith, i.e., $\theta=0 \mathrm{deg}$; all measurements were taken at an azimuth angle of 90 deg.

These radiometric quantities were then applied to estimate $R_{r s}\left(\mathrm{sr}^{-1}\right)$ spectra, using the spectral optimization approach proposed by Ref. 25, to remove surface-reflected radiance $\left[L_{r}(\lambda)\right]$. [6 $R_{r s}$ spectra, which were estimated through in situ hyperspectral measurements, were then resampled to simulate satellite data. The spectral response functions of each ocean and land colour instrument-Sentinel 3 band were used to derive band-weighted data. 


\subsection{Phytoplankton Absorption Coefficient $\left(a_{\varphi}\right)$, Detritus Plus CDOM Absorption Coefficient $\left(a_{C D M}\right)$, and Total Absorption Coefficient $\left(a_{t}\right)$}

To estimate CDOM absorption coefficient $\left(a_{\mathrm{CDOM}}, \mathrm{m}^{-1}\right)$, water samples were filtered through Whatman nylon membrane- $-0.22-\mu \mathrm{m}$ porosity and $47-\mathrm{mm}$ diameter. The absorbance of the filtrates was read using a 2600 UV-VIS spectrophotometer (Shimadzu, Japan), and the results were applied to calculate $a_{\mathrm{CDM}}$ as proposed by Ref. 27 [Eq. (11)]:

$$
a_{\mathrm{CDOM}}=2.3 \frac{\mathrm{OD}_{\mathrm{CDOM}}(\lambda)}{r}
$$

where $\operatorname{OD}_{\mathrm{CDOM}}(\lambda)$ is the optical density of CDOM and $r$ is the cuvette path length $(0$ and $1 \mathrm{~m})$.

To determine the total particulate (algal and detritus) absorption coefficient $\left(a_{p}, \mathrm{~m}^{-1}\right)$, water samples were filtered through fiberglass GF/F Whatman $-0.7-\mu \mathrm{m}$ porosity and $47-\mathrm{mm}$ diameter. Then, transmittance-reflectance (T-R) method described by Refs. 28 and 29 was employed using a double-beam 2600 UV-VIS spectrophotometer equipped with an integrating sphere. The spectral sampling ranged from 280 to $800 \mathrm{~nm}$, with a spectral resolution of $1 \mathrm{~nm}$. To bleach pigments from the filters, a 10\% sodium hypochlorite (NaCLO) solution was used and T-R measurements were taken again. By eliminating pigments influence, it was possible to obtain detritus absorption coefficient $\left(a_{d}, \mathrm{~m}^{-1}\right) ; a_{p}$ and $a_{d}$ are then obtained according to Eq. (2)):

$$
a_{p, d}(\lambda)=\frac{2.303 \times \mathrm{OD}_{p, d}(\lambda)}{V \times A},
$$

where $\mathrm{OD}_{p}(\lambda)$ is the optical density of total particulate, $\mathrm{OD}_{d}(\lambda)$ is the optical density of detritus, $V$ is the filtered volume $\left(\mathrm{m}^{3}\right)$, and $A$ is the filter clearance area $\left(\mathrm{m}^{2}\right)$. The phytoplankton absorption coefficients $\left(a_{\varphi}, \mathrm{m}^{-1}\right)$ were calculated by subtracting $a_{d}$ from $a_{p}$. Finally, $a_{\mathrm{CDM}}$ is calculated by adding $a_{\mathrm{CDOM}}$ to $a_{d}$.

The $a_{t}$ is calculated as the sum of the absorption coefficients of pure water $\left(a_{w}\right)$, phytoplankton $\left(a_{\varphi}\right)$, nonalgal particles $\left(a_{\mathrm{NAP}}\right)$, and CDOM $\left(a_{\mathrm{CDOM}}\right)$.

\subsection{Quasianalytical Algorithm}

$\mathrm{QAA}_{\mathrm{V} 5}$ and $\mathrm{QAA}_{\mathrm{V} 6}$ performances were evaluated for IHR. It is important to highlight that QAA $_{\mathrm{V} 6}$ was developed to improve QAA accuracy in water systems in which $R_{r s}$ at $670 \mathrm{~nm}$ is $>0.0015 \mathrm{sr}^{-1}$, i.e., coastal regions and areas with high sediments concentration. QAA $\mathrm{BBHR}_{\text {and }}$ $\mathrm{QAA}_{\mathrm{OMW}}$, the two reparameterized versions for Tietê River cascading system, were also tested. The dataset considered by Ref. 13 for QAABBHR parameterization presented high values and a broad range of Chl- $a$ concentration (from 17.7 to $797.8 \mathrm{mg} \mathrm{m}^{-3}$; average $274.5 \mathrm{mg} \mathrm{m}^{-3}$ ) and SPM concentration ranging from 3.6 to $44.0 \mathrm{~g} \mathrm{~m}^{-3}$ (average $14.6 \mathrm{~g} \mathrm{~m}^{-3}$ ), with its organic fraction corresponding to $\sim 90 \%$ of total SPM in the samples. Differently, the dataset used by Ref. 14 for QAA ${ }_{\mathrm{OMw}}$ parameterization showed low average Chl- $a$ concentration $\left(16.15 \mathrm{mg} \mathrm{m}^{-3}\right.$, ranging from 2.46 to $\left.38.59 \mathrm{mg} \mathrm{m}^{-3}\right)$, as well as low average SPM concentration $\left(1.85 \mathrm{~g} \mathrm{~m}^{-3}\right.$, varying from 0.10 to $5.30 \mathrm{~g} \mathrm{~m}^{-3}$ ); inorganic fraction was predominant in total SPM. Statistic metrics used to assess the QAAs performances for IHR were normalized root mean square error (NRMSE) and mean absolute percentage error (MAPE), considering $a_{\varphi}, a_{\mathrm{CDM}}$, and $a_{t}$ estimated from water samples obtained in the field campaign as reference data.

The main improvements applied by the authors to adequate QAA for BBHR were changing $\lambda_{0}$ to $709 \mathrm{~nm}$; calibration of $\chi$ and of the coefficients of the polynomial fit for empirical derivation of $a_{t}\left(\lambda_{0}\right)$; parameterization of $\xi$ based on in situ $a_{\mathrm{CDM}}$ spectral slope and empirical calibration of $\zeta$. These alterations aimed to adjust the model for the highly eutrophic environment of BBHR. Even presenting an oligo-to-mesotrophic status, the adjustment of $\lambda_{0}$ toward NIR region also showed to be satisfactory in NHR. To parameterize QAA for NHR, in addition to shifting $\lambda_{0}$, the combination of wavelengths in the equation for $\chi$ estimation was modified, as well as the wavelengths for $\eta$ calculation, which were calibrated based on in situ $a_{t}$ measurements. Considering local data, band ratio and the offset coefficient for $\zeta$ estimation were changed in $\mathrm{QAA}_{\mathrm{OMW}}$, along with $S$ optimization for $\xi$ derivation; final steps for obtaining $a_{\mathrm{CDM}}(\lambda)$ 


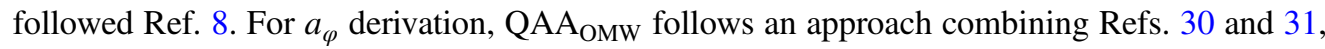
using in situ dataset to reproduce the spectral shape for $a_{\varphi}(\lambda)$.

\section{Results and Discussion}

\subsection{Water Quality Characterization}

Chl- $a$ and SPM concentrations varied widely (1.37 to $119.04 \mathrm{mg} \mathrm{m}^{-3}$ and 1.00 to $8.10 \mathrm{~g} \mathrm{~m}^{-3}$, respectively), showing significant spatial variability (Table (1). OSM represented $63 \%$ of the SPM, which means organic matter is slightly predominant. Turbidity values also showed some fluctuation, although it was lower than the variation presented by Chl- $a$ and SPM (coefficient of variation 23.28\%); in general, turbidity presented a relatively low average value (4.24 NTU). Secchi disk presented an average of $2.23 \mathrm{~m}$ and the lowest coefficient of variation $(15.50 \%)$.

Regarding the absorption coefficients, $a_{d}(443)$ and $a_{\varphi}(443)$ presented similar average values, whereas $a_{\mathrm{CDOM}}(443)$ presented the highest values $\longrightarrow a_{d}(443)$ and $a_{\varphi}(443)$. Detritus can be constituted of mineral matter, humus, or organic remains; considering that organic fraction of SPM showed to be slightly higher in this dataset and $a_{\varphi}$ is not dominant, detritus in the reservoir is probably mainly constituted of humus and organic remains that are not resulting from phytoplankton degradation. 22

\subsection{Bio-Optical Characterization}

In situ measured $R_{r s}$ spectra [Fig. 2(a)] show absorption features around $675 \mathrm{~nm}$ and a reflectance peak around $700 \mathrm{~nm}$ that can be associated with Chl- $a$. However, these $R_{r s}$ features are not

Table 1 Descriptive statistics of water quality parameters and optical data in IHR; SD, standard deviation; CV, coefficient of variation; $n=29$.

\begin{tabular}{llllll}
\hline \hline & Minimum & Maximum & Mean & SD & CV (\%) \\
\hline Chl-a $\left(\mathrm{mg} \mathrm{m}^{-3}\right)$ & 1.37 & 119.04 & 19.34 & 24.71 & 127.79 \\
SPM $\left(\mathrm{g} \mathrm{m}^{-3}\right)$ & 1.00 & 8.10 & 2.45 & 1.40 & 57.19 \\
OSM/SPM & 0.29 & 0.88 & 0.63 & 0.15 & 23.28 \\
ISM/SPM & 0.12 & 0.71 & 0.37 & 0.15 & 40.11 \\
Depth $(\mathrm{m})$ & 9.50 & 21.60 & 14.90 & 4.29 & 28.77 \\
Turbidity $(\mathrm{NTU})$ & 2.82 & 8.87 & 4.24 & 1.19 & 28.01 \\
Secchi depth $(\mathrm{m})$ & 1.60 & 3.20 & 2.23 & 0.35 & 15.50 \\
$a_{\varphi}(443)\left(\mathrm{m}^{-1}\right)$ & 0.06 & 1.88 & 0.30 & 0.36 & 120.44 \\
$a_{\mathrm{CDM}}(443)\left(\mathrm{m}^{-1}\right)$ & 1.06 & 2.78 & 1.61 & 0.30 & 18.64 \\
$a_{d}(443)\left(\mathrm{m}^{-1}\right)$ & 0.14 & 0.62 & 0.37 & 0.13 & 33.54 \\
$a_{\mathrm{CDOM}}(443)\left(\mathrm{m}^{-1}\right)$ & 0.69 & 2.17 & 1.24 & 0.30 & 24.18 \\
$a_{t}(443)\left(\mathrm{m}^{-1}\right)$ & 1.13 & 4.68 & 2.06 & 0.80 & 38.95 \\
\hline \hline
\end{tabular}

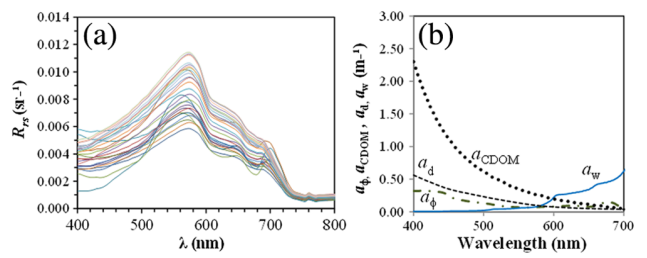

Fig. 2 (a) In situ $R_{r s}$ spectra and (b) average absorption coefficients by phytoplankton $\left(a_{\varphi}\right)$, CDOM $\left(a_{\mathrm{CDOM}}\right)$, detritus $\left(a_{d}\right)$ and pure water $\left(a_{w}\right) ; n=29$. 

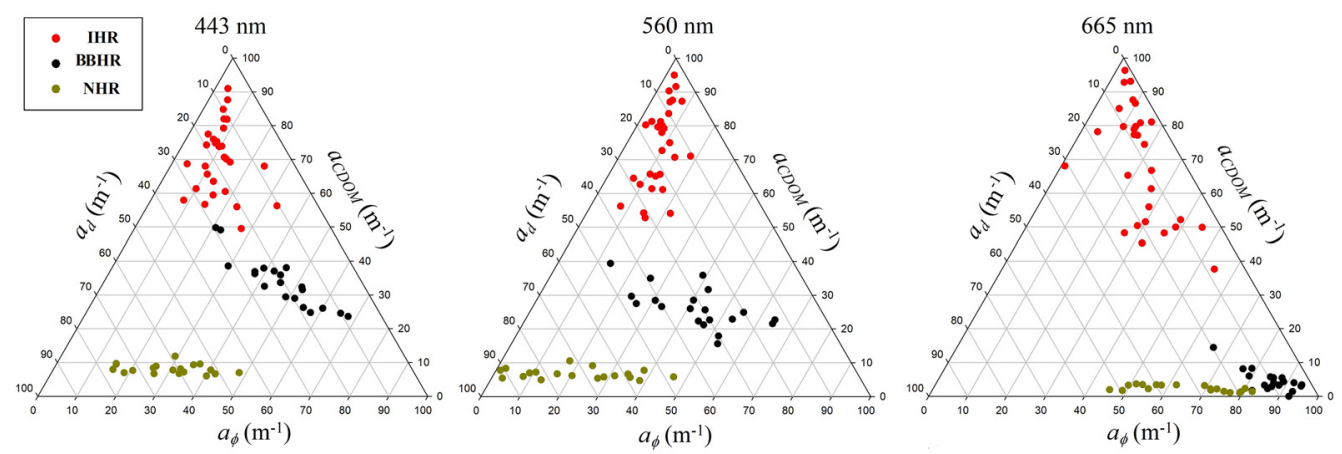

Fig. 3 Ternary plots presenting the relative contribution of detritus, phytoplankton and CDOM to the total absorption (without water fraction) at three different wavelengths for IHR (red dots), BBHR (black dots), and NHR (brown dots): for 443, 560, and $665 \mathrm{~nm}$.

observed in all stations, indicating spatial variability in terms of optically significant constituents (OSC) at IHR. A prominent feature of reflectance in the green spectral region, around $550 \mathrm{~nm}$, can be observed with different magnitudes [Fig. 2(a)]. This reflectance peak is usually related with scattering from algal cells, ${ }^{3}$ and also with ISM, which shifts higher reflectance values toward longer wavelengths. ${ }^{3}$ Average $a_{\mathrm{CDOM}}$ was the greatest contributor for $a_{t}$ until around $660 \mathrm{~nm}$ [Fig. 2(b)]. Average $a_{d}$ presented higher values than average $a_{\varphi}$ through blue and green spectral regions; approximately at $600 \mathrm{~nm}$ average $a_{\varphi}$ shows slight increase, and it is considerably greater than average $a_{d}$ from 660 to $700 \mathrm{~nm}$ [Fig. 2(b)].

Ternary plots (Fig. 3) display the relative contribution of $a_{\mathrm{CDOM}}, a_{\varphi}$, and $a_{d}$ to the total absorption at IHR. Similar datasets from BBHR ${ }^{1}$ and NHR, ${ }^{1}$ collected in May, 2014, and May, 2016, respectively, are also plotted for comparison purpose. It is relevant to highlight that all three dataset considered here were collected during the dry season.

Absorption in IHR dataset is dominated by CDOM in all three wavelengths here considered, corresponding to $70.11 \% \pm 3.94 \%$ at $443 \mathrm{~nm}, 73.63 \% \pm 4.67 \%$ at $560 \mathrm{~nm}$, and $68.94 \% \pm$ $6.43 \%$ at $665 \mathrm{~nm}$. Detritus contributed to the total absorption budget with $18.13 \% \pm 2.67 \%$ at $443 \mathrm{~nm}$ and $17.18 \% \pm 3.40 \%$ at $560 \mathrm{~nm}$. At $665 \mathrm{~nm}$, phytoplankton contributed with $20.08 \% \pm 5.27 \%$ of the total while detritus contributed with only $10.97 \% \pm 2.86 \%$. In BBHR, total absorption was predominately due to phytoplankton in all three wavelengths, especially at $665 \mathrm{~nm}$, with $a_{\varphi}$ contributing with $85.72 \% \pm 3.18 \%$. However, at 443 and $560 \mathrm{~nm}$ the total absorption is more balanced among all OSC as can be observed in the scatter of dots around the central area of the plots [Figs. B(a] and 3(b)]. In NHR dataset, otherwise, $a_{d}$ was the major contributor at 443 and $560 \mathrm{~nm}$, corresponding to $62.16 \% \pm 4.42 \%$ and $72.02 \% \pm 6.52 \%$, respectively. At $665 \mathrm{~nm}, a_{\varphi}$ represented $65.15 \% \pm 5.97 \%$ of total absorption, whereas $a_{d}$ was the second greatest contributor with $32.51 \% \pm 5.72 \%$.

\subsection{QAA Performances}

\subsubsection{Absorption coefficient of phytoplankton $\left(a_{\varphi}\right)$}

QAA $_{\text {OMw }}$ presented the lowest average NRMSE (\%) and MAPE $\left(\mathrm{m}^{-1}\right)$ for $a_{\varphi}$ retrieval (Table [). However, if we consider only $665-\mathrm{nm}$ band, which is a diagnosis wavelength for Chl- $a$, this same version shows the highest errors $\left(\mathrm{NMRSE}=31.74 \%\right.$, MAPE $=6.03 \mathrm{~m}^{-1}$ ).

$\mathrm{QAA}_{\mathrm{OMW}}$ tuning was based on NHR dataset, comprising Chl- $a$ concentration values lower than the ones measured in IHR (NHR average $7.94 \mathrm{mg} \mathrm{m}^{-3}$; IHR average $19.34 \mathrm{mg} \mathrm{m}^{-3}$ ), and this difference can be related to its poor performance at $665-\mathrm{nm}$ band. $\mathrm{QAA}_{\mathrm{BBHR}}$, differently, was developed for a highly productive reservoir, and IHR bio-optical status did not showed to be similar to BBHR one, justifying why it was not completely suitable for retrieving $a_{\varphi}$ in IHR. QAA $_{V 6}$ showed higher values of NRMSE and MAPE than QAA $_{V 5}$ in all wavelengths, although this performance was not initially expected as $\mathrm{QAA}_{\mathrm{V} 6}$ was proposed for $R_{r s}$ $(670)>0.0015 \mathrm{sr}^{-1}$, which fits IHR dataset $\left[R_{r s}(670)=0.00427 \mathrm{sr}^{-1}\right]$. Comparatively, 
Table 2 QAAs performances for $a_{\varphi}$ retrieval, according to each band, based on NRMSE (\%) and $\operatorname{MAPE}\left(\mathrm{m}^{-1}\right)$.

\begin{tabular}{|c|c|c|c|c|c|c|c|c|}
\hline \multirow[b]{2}{*}{ Bands (nm) } & \multicolumn{2}{|c|}{$\mathrm{QAA}_{\mathrm{V} 5}$} & \multicolumn{2}{|c|}{$\mathrm{QAA}_{\mathrm{V} 6}$} & \multicolumn{2}{|c|}{$\mathrm{QAA}_{\mathrm{BBHR}}$} & \multicolumn{2}{|c|}{$\mathrm{QAA}_{\mathrm{OMw}}$} \\
\hline & $\begin{array}{l}\text { NRMSE } \\
(\%)\end{array}$ & $\begin{array}{l}\text { MAPE } \\
\left(\mathrm{m}^{-1}\right)\end{array}$ & $\begin{array}{c}\text { NRMSE } \\
(\%)\end{array}$ & $\begin{array}{l}\text { MAPE } \\
\left(m^{-1}\right)\end{array}$ & $\begin{array}{l}\text { NRMSE } \\
(\%)\end{array}$ & $\begin{array}{l}\text { MAPE } \\
\left(\mathrm{m}^{-1}\right)\end{array}$ & $\begin{array}{l}\text { NRMSE } \\
(\%)\end{array}$ & $\begin{array}{c}\text { MAPE } \\
\left(\mathrm{m}^{-1}\right)\end{array}$ \\
\hline 412 & 14.04 & 1.36 & 17.14 & 1.93 & 19.46 & 0.70 & 21.94 & 1.84 \\
\hline 443 & 15.86 & 1.35 & 19.82 & 1.91 & 13.80 & 0.86 & 21.02 & 1.15 \\
\hline 490 & 30.77 & 2.44 & 40.53 & 3.29 & 30.86 & 2.46 & 26.07 & 0.98 \\
\hline 510 & 32.46 & 2.61 & 44.12 & 3.58 & 35.94 & 2.86 & 19.92 & 0.67 \\
\hline 560 & 38.14 & 3.21 & 54.41 & 4.55 & 49.70 & 4.03 & 20.49 & 0.60 \\
\hline 620 & 14.19 & 1.38 & 21.25 & 3.49 & 20.01 & 3.48 & 16.07 & 0.84 \\
\hline 665 & 15.35 & 1.19 & 20.23 & 4.09 & 18.06 & 5.46 & 31.74 & 6.03 \\
\hline 681 & 15.49 & 0.78 & 19.17 & 2.32 & 14.03 & 2.56 & 23.79 & 1.94 \\
\hline 709 & 112.00 & 3.78 & 118.04 & 10.99 & 89.48 & 10.70 & 30.64 & 0.45 \\
\hline Average & 32.03 & 2.01 & 39.41 & 4.02 & 32.37 & 3.68 & 23.52 & 1.61 \\
\hline
\end{tabular}
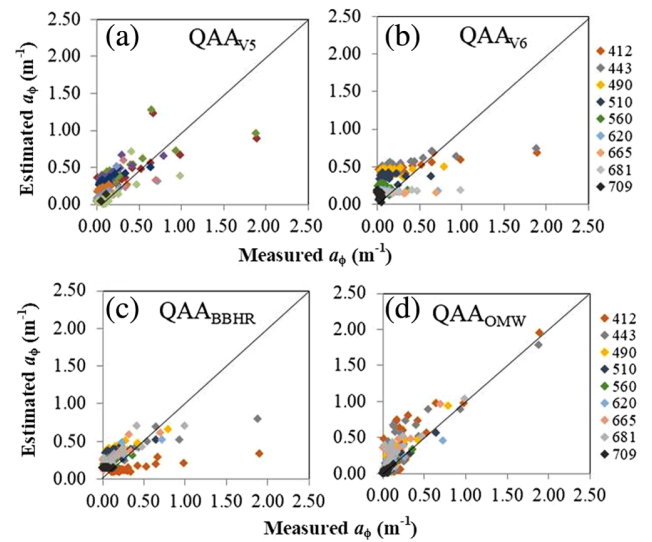

Fig. 4 Comparison between estimated and measured $a_{\varphi}$ using: (a) $Q A A_{V 5}$, (b) $Q A A_{V 6}$, (c) $\mathrm{QAA}_{\mathrm{BBHR}}$, and (d) $\mathrm{QAA}_{\mathrm{OMW}}$.

QAA $_{\mathrm{V} 5}$ showed to be the most accurate version at $665 \mathrm{~nm}$ (NMRSE $=15.35 \%$, MAPE $=1.19 \mathrm{~m}^{-1}$ ).

Scatterplots of $a_{\varphi}$ estimated by the QAAs and $a_{\varphi}$ measured in the laboratory are shown in Fig. 6 . In general, QAA $\mathrm{V}_{5}$ overestimated $a_{\varphi}$ in great part of wavelengths [Fig. A(a)], except for the longer ones-specifically 681 and $709 \mathrm{~nm}$ - for which the version underestimated the values. The other versions overestimated most of the $a_{\varphi}$ values at all wavelengths, excluding QAA $\mathrm{BBHR}_{\mathrm{B}}$ at $412 \mathrm{~nm}$. It can be clearly observed that a sampling spot disagrees with the other ones in almost all wavelengths for all four QAA tested; this spot corresponds to the highest Chl- $a$ and SPM concentrations of the dataset.

\subsubsection{Absorption coefficient of CDOM plus detritus ( $a_{\mathrm{CDM}}$ )}

For $a_{\mathrm{CDM}}$, all QAAs variants demonstrated similar average NRMSE and MAPE, presenting reasonable accuracy (Table B). An improvement in the NRMSE values can be observed with increasing wavelengths. $\mathrm{QAA}_{\mathrm{OMW}}$ showed slight better results $(\mathrm{NRMSE}=21.74 \%, \mathrm{MAPE}=$ $0.44 \mathrm{~m}^{-1}$ ); NHR is a nonproductive reservoir and it is dominated by $a_{\mathrm{CDM}}$ in the blue-green 
Table 3 QAAs performances for $a_{\mathrm{CDM}}$ retrieval, according to each band, based on NRMSE (\%) and MAPE $\left(\mathrm{m}^{-1}\right)$.

\begin{tabular}{|c|c|c|c|c|c|c|c|c|}
\hline \multirow[b]{2}{*}{ Bands (nm) } & \multicolumn{2}{|c|}{$\mathrm{QAA}_{\mathrm{V} 5}$} & \multicolumn{2}{|c|}{$\mathrm{QAA}_{\mathrm{V} 6}$} & \multicolumn{2}{|c|}{$\mathrm{QAA}_{\mathrm{BBHR}}$} & \multicolumn{2}{|c|}{$\mathrm{QAA}_{\mathrm{OMW}}$} \\
\hline & $\begin{array}{c}\text { NRMSE } \\
(\%)\end{array}$ & $\begin{array}{l}\text { MAPE } \\
\left(\mathrm{m}^{-1}\right)\end{array}$ & $\begin{array}{c}\text { NRMSE } \\
(\%)\end{array}$ & $\begin{array}{l}\text { MAPE } \\
\left(\mathrm{m}^{-1}\right)\end{array}$ & $\begin{array}{c}\text { NRMSE } \\
(\%)\end{array}$ & $\begin{array}{l}\text { MAPE } \\
\left(\mathrm{m}^{-1}\right)\end{array}$ & $\begin{array}{c}\text { NRMSE } \\
(\%)\end{array}$ & $\begin{array}{c}\text { MAPE } \\
\left(\mathrm{m}^{-1}\right)\end{array}$ \\
\hline 412 & 50.41 & 0.85 & 49.60 & 0.84 & 41.17 & 0.67 & 29.49 & 0.35 \\
\hline 443 & 40.71 & 0.87 & 40.26 & 0.86 & 34.54 & 0.70 & 24.64 & 0.31 \\
\hline 490 & 32.75 & 0.91 & 32.56 & 0.90 & 29.54 & 0.78 & 21.43 & 0.33 \\
\hline 510 & 30.46 & 0.92 & 30.33 & 0.91 & 28.07 & 0.81 & 20.69 & 0.34 \\
\hline 560 & 25.94 & 0.95 & 25.89 & 0.94 & 24.83 & 0.86 & 19.71 & 0.39 \\
\hline 620 & 23.52 & 0.97 & 23.50 & 0.97 & 23.07 & 0.92 & 19.82 & 0.49 \\
\hline 665 & 22.42 & 0.98 & 22.41 & 0.98 & 22.20 & 0.95 & 19.98 & 0.57 \\
\hline 681 & 21.91 & 0.98 & 21.91 & 0.98 & 21.74 & 0.96 & 19.85 & 0.58 \\
\hline 709 & 21.65 & 0.99 & 21.65 & 0.99 & 21.54 & 0.97 & 20.07 & 0.64 \\
\hline Average & 29.97 & 0.94 & 29.79 & 0.93 & 27.41 & 0.85 & 21.74 & 0.44 \\
\hline
\end{tabular}

region, just as IHR, and this can be associated with the lower errors presented by $\mathrm{QAA}_{\mathrm{OMW}}$. As generally the estimation of $a_{\mathrm{CDM}}$ form remotely sensed data uses the wavelength of 443 , the lowest NRMSE was observed for $\mathrm{QAA}_{\mathrm{OMW}}$ version.

Figure 5 shows that $\mathrm{QAA}_{\mathrm{V} 5}, \mathrm{QAA}_{\mathrm{V} 6}$, and $\mathrm{QAA} \mathrm{BBHR}_{\mathrm{BBH}}$ consistently underestimated $a_{\mathrm{CDM}}$ in all wavelengths. It probably occurs due to high $\mathrm{CDOM}$ and detritus concentrations and its relative predominance in the absorption budget of IHR (see Fig. 3), which is not commonly found in ocean and coastal waters, and also differs from BBHR optical characteristics. In these scatterplots, two sampling spots evidently differ from the others: one of them is discrepant in all wavelengths and also corresponds to the spot with the highest Chl- $a$ and SPM concentrations (as in Fig. (7), whereas the second one disagrees mostly in the shortest wavelengths - except for QAA ${ }_{\mathrm{OMW}}$, which overestimated $a_{\mathrm{CDM}}$ values for all wavelengths - and it corresponds to the second-highest SPM concentration in the dataset.

On the other hand, QAA $\mathrm{OMW}_{\mathrm{O}}$ was able to retrieve, in general, more consistent values of $a_{\mathrm{CDM}}$ [Fig. 5(d)]. It is important here to highlight that QAA approach unifies absorption by detritus and CDOM as $a_{\mathrm{CDM}}$. Taking this into account, and also considering that NHR absorption occurs mostly due to detritus, while in IHR the CDOM is predominant, it corroborates the capability
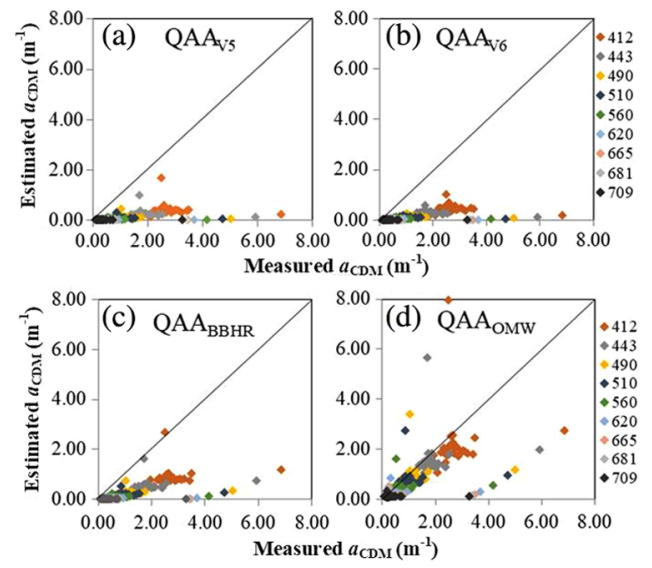

Fig. 5 Comparison between estimated and measured $a_{C D M}$ using: (a) $Q A A_{V 5}$, b) $Q A A_{V 6}$, (c) QAA $\mathrm{BBHR}_{\mathrm{B}}$, and (d) QAA $\mathrm{OMw}$. 
Table 4 QAAs performances for $a_{t}$ retrieval, according to each band, based on NRMSE (\%) and $\operatorname{MAPE}\left(\mathrm{m}^{-1}\right)$.

\begin{tabular}{|c|c|c|c|c|c|c|c|c|}
\hline \multirow[b]{2}{*}{$\begin{array}{l}\text { Bands } \\
(\mathrm{nm})\end{array}$} & \multicolumn{2}{|c|}{$\mathrm{QAA}_{\mathrm{V} 5}$} & \multicolumn{2}{|c|}{$\mathrm{QAA}_{\mathrm{V} 6}$} & \multicolumn{2}{|c|}{$\mathrm{QAA}_{\mathrm{BBHR}}$} & \multicolumn{2}{|c|}{$\mathrm{QAA}_{\mathrm{OMW}}$} \\
\hline & $\begin{array}{c}\text { NRMSE } \\
(\%)\end{array}$ & $\begin{array}{l}\text { MAPE } \\
\left(\mathrm{m}^{-1}\right)\end{array}$ & $\begin{array}{c}\text { NRMSE } \\
(\%)\end{array}$ & $\begin{array}{l}\text { MAPE } \\
\left(\mathrm{m}^{-1}\right)\end{array}$ & $\begin{array}{c}\text { NRMSE } \\
(\%)\end{array}$ & $\begin{array}{l}\text { MAPE } \\
\left(\mathrm{m}^{-1}\right)\end{array}$ & $\begin{array}{c}\text { NRMSE } \\
(\%)\end{array}$ & $\begin{array}{c}\text { MAPE } \\
\left(\mathrm{m}^{-1}\right)\end{array}$ \\
\hline 412 & 55.76 & 2.88 & 53.59 & 2.26 & 50.41 & 1.93 & 32.97 & 0.41 \\
\hline 443 & 42.51 & 2.06 & 40.90 & 1.60 & 37.10 & 1.30 & 24.41 & 0.27 \\
\hline 490 & 36.00 & 1.36 & 33.54 & 1.01 & 29.19 & 0.78 & 17.26 & 0.18 \\
\hline 510 & 34.56 & 1.27 & 32.15 & 0.94 & 27.78 & 0.71 & 16.37 & 0.18 \\
\hline 560 & 31.67 & 0.97 & 29.35 & 0.71 & 24.56 & 0.49 & 17.23 & 0.18 \\
\hline 620 & 28.52 & 0.58 & 27.42 & 0.37 & 20.78 & 0.20 & 18.73 & 0.16 \\
\hline 665 & 25.43 & 0.43 & 24.49 & 0.24 & 16.02 & 0.11 & 15.89 & 0.13 \\
\hline 681 & 21.84 & 0.40 & 22.16 & 0.27 & 15.72 & 0.13 & 16.15 & 0.16 \\
\hline 709 & 78.17 & 0.27 & 66.89 & 0.17 & 28.39 & 0.07 & 33.05 & 0.08 \\
\hline Average & 39.38 & 1.14 & 36.72 & 0.84 & 27.77 & 0.63 & 21.34 & 0.19 \\
\hline
\end{tabular}

of QAA $\mathrm{OMW}_{\mathrm{W}}$ in retrieving $a_{\mathrm{CDM}}$ in nonphytoplankton-dominated waters and, consequently, its potential in determining carbon content in aquatic systems.

\subsubsection{Total absorption coefficient $\left(a_{t}\right)$}

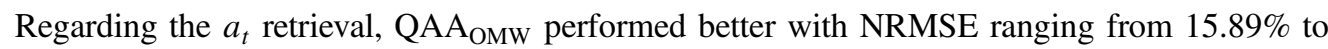
$32.97 \%$ (average of $21.34 \%$ ) and $\mathrm{QAA}_{\mathrm{V} 5}$ was the one that presented the highest errors with $55.76 \%$ at $412 \mathrm{~nm}$ and average NRMSE of $39.38 \%$ (Table $\emptyset$ ). The second best performance was observed for $\mathrm{QAA}_{\mathrm{BBHR}}$ with NRMSE ranging from $15.72 \%$ to $50.51 \%$ (average of $27.77 \%$ ). $\mathrm{QAA}_{\mathrm{OMW}}$ great performance for $a_{t}$ correlates with its good average results for $a_{\varphi}$ and $a_{\mathrm{CDM}}$, demonstrating that indeed, both initial steps for $a_{t}$ estimation and the last ones-partitioning of $a_{t}$ into $a_{\varphi}$ and $a_{\mathrm{CDM}}$-in $\mathrm{QAA}_{\mathrm{OMW}}$ parameterization showed to be fairly adequate for IHR characteristics.

According to Tables 目 and 3, the highest errors for lower wavelengths observed in Table $\mathrm{A}$ were due to the estimation of $a_{\mathrm{CDM}}$. The QAAs performed better for $a_{\varphi}$ in lower wavelengths than in the longer ones. Scatterplots of $a_{t}$ estimated by the QAAs and $a_{t}$ measured in laboratory are shown in Fig. 6. These graphs show that the performance of $\mathrm{QAA}_{\mathrm{OMW}}$ outperformed the other QAA versions.
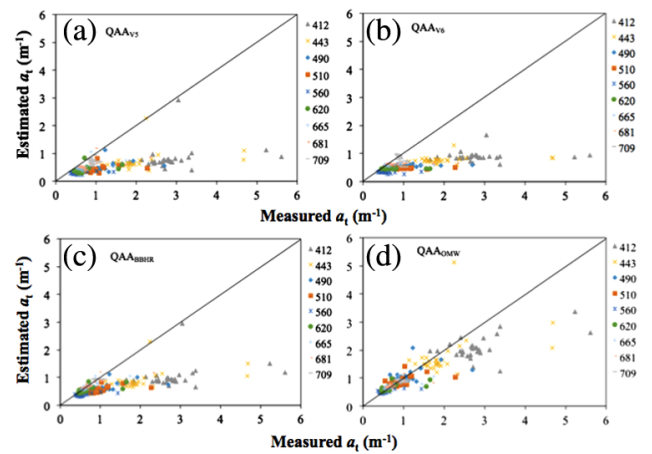

Fig. 6 Comparison between estimated and measured $a_{t}$ using: (a) $Q A A_{V 5}$, (b) $Q A A_{V 6}$, (c) QAA $\mathrm{BBHR}_{\mathrm{B}}$, and (d) QAA $\mathrm{OMw}$. 


\subsubsection{Implications for OSC monitoring}

Neither originals nor reparameterized QAA versions tested here were capable of estimating accurately the absorption coefficients in all wavelengths. This shows a challenge in copying with high optical variability in cascading system. Although QAA $\mathrm{BBHR}_{\mathrm{B}}$ was parameterized for a high productive aquatic system, the model could not accurately retrieve the $a_{\varphi}$ at $665 \mathrm{~nm}$ $\left[a_{\varphi}(665)\right]$, which is used as a proxy to estimate Chl- $a$ concentration. This possibly happened because Chl- $a$ concentration in BBHR is very high $\left(\sim 797 \mathrm{mg} \mathrm{m}^{-3}\right)$, and due to this the $R_{r s}$ spectra are masked by the package effect, as reported by Ref. 35. For $a_{\varphi}(665)$, the QAA 5 presented the lowest error. On the other hand, to estimate the $a_{\mathrm{CDM}}$ at $443 \mathrm{~nm}\left[a_{\mathrm{CDM}}(443)\right]$, which is a proxy for carbon content ${ }^{36}$ the $\mathrm{QAA}_{\mathrm{OMW}}$ presented the lowest error. These results highlighted the limitation of such quasianalytical scheme to monitor the spatial-temporal OSC in the cascading system. However, the obtained results also demonstrate an opportunity to better understand the complexity of these aquatic systems and try to figure out how to improve the QAA to use only one version to estimate the OSC in the entire cascade. Up to now, the monitoring of OSCs from space operationally is still a challenge.

\section{Conclusion}

As QAA native versions, $\mathrm{QAA}_{\mathrm{V} 5}$ and $\mathrm{QAA}_{\mathrm{V} 6}$, were designed for ocean and coastal waters, a poor performance for optically complex inland waters was already expected and it was confirmed. However, QAA $A_{B B H R}$ did not performed satisfactorily as supposed, demonstrating that even presenting some similarity regarding the OSCs, the bio-optical status of BBHR and IHR are substantially different and, thus, IHR IOPs cannot be derived through this reparameterized QAA. Therefore, our hypothesis can be rejected as QAA $\mathrm{BBHR}_{\text {B }}$ was not suitable for retrieving neither $a_{\varphi}$ nor $a_{\mathrm{CDM}}$. Although QAA $\mathrm{OMW}_{\mathrm{O}}$ was able to retrieve relatively accurate average values for $a_{\varphi}$ and $a_{\mathrm{CDM}}$ values in IHR, in addition performing relatively well for $a_{\mathrm{CDM}}(443)$, it presented an unsuitable performance for $a_{\varphi}(665)$, indicating that this version also has its limitations for deriving IHR IOPs at wavelengths used as proxy for OSCs concentrations estimation. Variability of bio-optical characteristics along the cascading system was confirmed as none reparameterized version for reservoirs in the same system was completely suitable for IHR in all wavelengths. Even though the algorithms did not performed satisfactorily in all wavelengths, results for specific wavelengths show potential when it comes to OSCs concentration retrieval. We can highlight the good, it is possible to point out the good QAA $\mathrm{V}_{5}$ performance for $a_{\varphi}(665)$ estimation and QAA $\mathrm{OMW}_{\mathrm{O}}$ performance for $a_{\mathrm{CDM}}(443)$. These results demonstrate the possibility of using QAA versions that showed to be suitable for a particular absorption coefficient at a certain wavelength for an application that relates to it, using them as a proxy and then applying it to estimate the OSC in inland waters from space. In any case, further research is necessary, either aiming to achieve a QAA reparameterization appropriate for waters with widely differing optical properties or analyzing the suitability of other analytical methods.

\section{Disclosures}

No potential conflict of interest was reported by the authors.

\section{Acknowledgments}

The authors thank FAPESP Projects (Process Nos. 2012/19821-1 and 2015/21586-9) and Professor Edivaldo Velini and staffs from FCA/UNESP for allowing the use of their laboratory facilities.

\section{References}

1. Z. Lee, K. L. Carder, and R. A. Arnone, "Deriving inherent optical properties from water color: a multiband quasi-analytical algorithm for optically deep waters," Appl. Opt. 41, 5755-5772 (2002). 
2. D. Odermatt et al., "Remote sensing of environment review of constituent retrieval in optically deep and complex waters from satellite imagery," Remote Sens. Environ.118, 116-126 (2012).

3. A. Morel, "In-water and remote measurements of ocean color," Boundary Layer Meteorol. 18, 177-201 (1980).

4. K. L. Carder et al., "Semianalytic moderate-resolution imaging spectrometer algorithms for chlorophyll a and absorption with bio-optical domains based on nitrate-depletion temperatures," T. Geophys. Res. 104, 5403-5421 (1999).

5. C. F. Le et al., "Validation of a quasi-analytical algorithm for highly turbid eutrophic water of Meiliang Bay in Taihu Lake, China," EEEE Trans. Geosci. Remote Sens. 47, 2492-2500 (2009).

6. W. Yang et al., "Retrieval of inherent optical properties for turbid inland waters from remote-sensing reflectance," EEEE Trans. Geosci. Remote Sens. 51, 3761-3773 (2013).

7. S. Mishra et al., "Quantifying cyanobacterial phycocyanin concentration in turbid productive waters: A quasi-analytical approach," Remote Sens. Environ. 133, 141-151 (2013).

8. S. Mishra, D. R. Mishra, and Z. Lee, "Bio-optical inversion in highly turbid and cyanobacteria-dominated waters," IEEE Trans. Geosci. Remote Sens. 52, 375-388 (2014).

9. L. Li et al., "An inversion model for deriving inherent optical properties of inland waters: Establishment, validation and application," Remote Sens. Environ. 135, 150-166 (2013).

10. L. Li, L. Li, and K. Song, "Remote sensing of freshwater cyanobacteria: An extended IOP Inversion of Inland Waters (IIMIW) for partitioning absorption coefficient and estimating phycocyanin," Remote Sens. Environ. 157, 9-23 (2015).

11. F. A. R. Barbosa et al., "The cascading reservoir continuum concept (CRCC) and its application to the 320 river Tietê-basin, São Paulo State, Brazil," in Workshop on Theoretical Reservoir Ecology and its Applications, pp. 425-437 (1999).

12. W. S. Smith, E. L. G. Espíndola, and O. Rocha, "Environmental gradient in reservoirs of the medium and low Tietê River: limnological differences through the habitat sequence," Acta Limnol. Bras. 26, 73-88 (2014).

13. F. S. Y. Watanabe et al., "Parameterization and calibration of a quasi-analytical algorithm for tropical eutrophic waters," ISPRS J. Photogramm. Remote Sens. 121, 28-47 (2016).

14. T. W. P. Rodrigues, "From oligo to eutrophic inland waters: advancements and challenges for bio-optical modeling," Doctoral dissertation, https://repositorio/unesplbr/bitstream handle/11449/150315/rodrigues_twp_dr_prudlpdf?sequence=3\&isAllowed=y (2017).

15. M. J. Dellamano-Oliveira et al., "Phytoplankton taxonomic composition and temporal changes in a tropical reservoir," Fundam. Appl. Limnol. 171, 27-38 (2008).

16. C. T. Cairo et al., "Spatial and seasonal variation in diffuse attenuation coefficients of downward irradiance at Ibitinga Reservoir, São Paulo, Brazil," Hydrobiologid 784, 265-282 (2017).

17. Z. Lee et al., "An update of the quasi-analytical algorithm (QAA_v5)," in International Ocean Color Group Software Report (IOCCG), 2009, http://www.ioccg.org/groups, Software_OCA/QAA_v5.pdt

18. Z. Lee, "Update of the quasi-analytical algorithm (QAA_v6)," in International Ocean Color Group Software Report (IOCCG), 2014, http://www/ioccg.org/groups/Software_OCA] QAA_v6_2014209.pdA.

19. C. Guimarães, Jr et al., "Aspectos limnológicos do reservatório de Ibitinga-SP," Braz. J. Water Resour. 3, 89-103 (1998).

20. E. M. L. M. Novo et al., "Proposal for a remote sensing trophic state index based upon Thematic Mapper/Landsat images," Rev. Ambient. Agud 8, 65-82 (2013).

21. H. L. Golterman, R. S. Clymo, and M. A. M. Ohnstad, Methods for Physical and Chemical Analysis of Fresh Waters, Blackwell Scientific, Oxford (1978).

22. C. J. Lorenzen, "Determination of chlorophyll and pheo-pigments: spectrophotometric equations," Limnol. Oceanogr. 12, 343-346 (1967).

23. APHA, Standard Methods for the Examination of Water and Wastewater, American Public Health Association (APHA). American Water Works Association (AWWA), Water Environmental Federation (WEF), Washington (1998). 
24. C. D. Mobley, "Estimation of the remote-sensing reflectance from above-surface measurements," Appl. Opt. 38, 7442-7455 (1999).

25. Z. Lee et al., "Hyperspectral remote sensing for shallow waters: 2 deriving bottom depths and water properties by optimization," Appl. Opt. 38, 3831-3843 (1999).

26. Z. Lee et al., "Removal of surface-reflectance light for the measurement of remote sensing reflectance from an above-surface platform," Opt. Express 18, 26313-26324 (2010).

27. A. Bricaud, A. Morel, and L. Prieur, "Absorption by dissolved organic matter of the sea (yellow substance) in the UV and visible domains," Limnol. Oceanogr. 26, 43-53 (1981).

28. S. Tassan and G. M. Ferrari, "An alternative approach to absorption measurement of aquatic particles retained on filters," Limnol. Oceanogr. 40, 1358-1368 (1995).

29. S. Tassan and G. M. Ferrari, "Measurement of light absorption by aquatic particles retained on filters: determination of the optical path length amplification by the 'transmittancereflectance' method," J. Plankton Res. 20, 1699-1709 (1998).

30. C. S. Roesler, M. J. Perry, and K. L. Carder, "Modeling in situ phytoplankton absorption from total absorption spectra in productive inland marine waters," Limnol. Oceanogr. 34, 1510-1523 (1989).

31. Z. Lee et al., "Uncertainties of optical parameters and their propagations in an analytical ocean color inversion algorithm," Appl. Opt. 49, 369-381 (2010).

32. B. B. Prézelin et al., "The control of the production process of phytoplankton by the physical structure of the aquatic environment with special reference to its optical properties," Aquat. Sci. 53, 136-186 (1991).

33. A. A. Gitelson, "The peak near $700 \mathrm{~nm}$ on radiance spectra of algae and water: relationships of its magnitude and position with chlorophyll concentration," Int. J. Remote Sens. 13, 3367-3373 (1992).

34. L. Han and D. C. Rundquist, "Comparison of NIR/RED ratio and first derivative of reflectance in estimating algal-chlorophyll concentration: a case study in a turbid reservoir," Remote Sens. Environ. 62, 253-261 (1997).

35. E. H. Alcântara et al., "An investigation into the phytoplankton package effect on the chlorophyll-a specific absorption coefficient in Barra Bonita reservoir," Brazil Remote Sens. Lett. 7, 761-770 (2016).

36. Z. Wen et al., "Differences in the distribution and optical properties of DOM between fresh and saline lakes in a semi-arid area of Northern China," Aquat. Sci. 80, 1-12 (2018).

Biographies for the authors are not available. 